artist is at all original in his approach to the subject. For this reason "Flints and Fungus" (No. 180) and "Apple Log" (No. 221) are worthy of examination. Both are by Dudley Holland and neither is particularly well hung.

"Concarneau Harbour" by Murray Urquhart (No. 283) is painted in an impressionist manner, and with an impressionist palette. It illustrates once again how well suited this method is for outdoor subjects. A more modern way of dealing with buildings and trees is seen in "Houses by the New River" by Greta Ward (No. 88) and "West Hill, Highgate Village" by Peter Lowry (No. 864). In these there is little of the traditional recession of the planes; instead the artists give us a statement of the relationship of the various objects to each other when projected into one plane, the plane of the canvas or paper. Another picture of some interest is "Chelsea Terrace: Evening" by Robin Clifford (No. 176) which is in complete contrast to the two just mentioned. Where they tend to romance this tends to the factual, where they are relatively gay in colour this is drab, but the idiom is modernistic and not very comfortable.

One of the chief charms of water-colour drawings is that they possess a freshness and sparkle unobtainable in any other medium. Whether applied as washes or as blobs, water-colours are pre-eminent for rapid sketches; but they demand a skill and knowledge which will enable the artist to lay on the correct colour by first intention in the proper place, and afterwards to leave it alone. Any other way is apt to destroy the transparency of the medium and to lead to a muddiness which seems to be creeping back into modern practice. This is coming about through a revival of the old custom of applying an overall wash of yellow to the paper before starting work. Certain subjects benefit from this method, but as a general rule it leads to an undesirable lowering of tone. A more modern technique is to make slight sketches in pen or pencil and to do no more than indicate the artist's awareness of colour by means of occasional plain washes. To this class belong "Back Gardens" by Julia Morley (No. 748), and "Fête" by C. Bendall (No. 787) who has succeeded in conveying the movement of the dancing crowd in a convincing way.

The drawings and etchings in Gallery IX are pleasantly mixed. They range from the lively naturalism of Winifred Austen's "Marsh Tit" (No. 1054) through C. F. Tunnicliffe's "Wood Owl" (No. 1077) to "Nether Warden" by Clifford Webb (No. 1073) and "Rock Pool" by A. S. H. Mills (No. 1079). A drawing of "Professor J. T. Randall" by H. A. Freeth (No. 1008 ) is among the best of the portraits.

Architecture is not prominent this year: the number of exhibits is small compared with what one might have expected at a time when reconstruction is so much to the fore, but this is possibly a reflexion of the prevailing uncertainties of the situation. The majority of the plans are for public buildings. Plans for dwelling-houses are rare, but there are several blocks of flats, and housing schemes for local authorities.

Some of the animal studies in the sculpture gallery are good. I particularly liked "Gnu" by H. W. Palliser (No. 1172), "Ocelot" by Pamela Ascherson (No. 1255) and "Sleeping Cat" by W. G. Simmonds (No. 1262). Young artiodactyls seem to have an attraction for sculptors at the present time. This year we have "Lambs" by Rosamund Fletcher (No. 1202), "Fawn" by Faust Lang (No. 1205) and "Water Hole" by Alfred Oakley (No. 1208). The animal in the last-named piece has a tail which closely resembles that of a horse, and in this feature bears no resemblance to the young of any known ruminant.

Taken as a whole, this year's exhibition is disappointing. One has the feeling that artists, like other people, are tired and in need of inspiration rather than already in possession of it, or, at least, that they have not yet adjusted themselves to the conditions which are the legacy of war. To this many of them would possibly retort with Renoir's saying, "I have no theories; I paint for the sake of painting"'. They are the ones who, I suggest, will most rapidly find themselves again.

\title{
NEW FOREIGN MEMBERS OF THE ROYAL SOCIETY
}

A S announced briefly in Nature of May 18, p. 651, the following have been elected foreign members of the Royal Society :

\section{Dr. Herbert S. Gasser}

DR. Herbert S. GASSER, director of the Rockefeller Institute of New York, gave a new impetus to the physiology of the nervous system by his development of the technique of valve amplification and of recording with the cathode ray oscillograph, and by the exact analysis of the nerve action potential which he carried out with Prof. J. Erlanger. Making full use of the extended range of measurement, Gasser and Erlanger were able to show the composite nature of the action potential of a mixed nerve trunk and to measure the rates of conduction and the form of the electric response in the different types of nerve fibre. This work, for which they were awarded the Nobel Prize for Medicine in 1944, has led to a greatly increased understanding both of the biophysics of nerve and of the function of the different types of nerve fibre. It is now the basis of the exact studies of conduction within the central nervous system which are throwing fresh light on reflex activity.

Dr. Gasser is so well known to physiologists in Great Britain that his great personal influence and his successful direction of a famous institute need no comment. But his work for the joint war effort will be remembered, and in particular his many kindnesses to British men of science visiting the United States during the war period.

\section{Prof. Frédéric Joliot}

THE election of Prof. F. Joliot to the foreign membership of the Royal Society, at the exceptionally early age of forty-five, is a sign of the great admiration and regard in which he is held by his British colleagues. Prof. Joliot occupies a place in the contemporary world which has no exact parallel; there must be few who can combine eminence as a scientific worker, administrator and man-of-affairs in such a high degree. As an experimental physicist he has shown the most fertile imagination and skill. Together with his wife, Irene Curie, he discovered 
artificial radioactivity. When Rutherford congratulated them on this achievement, he said that he had himself sought for this phenomenon for thirty years. He had not succeeded in finding it, and this made him all the more appreciative of their success. Joliot's contributions towards the discovery of the neutron, of the properties of the positron, and of the phenomenon of materialization are notable. His experimental proof that more than one neutron is emitted in the fission of the uranium atom was a major step towards the invention of the atomic bomb.

Joliot had accomplished all this before the outbreak of war in 1939. During the occupation of France he became the head of the Front National, the resistance movement with more than one million members. At the same time, he directed brilliant researches on the application of radioactive tracer elements to biological problems; in particular, to the chemistry of iodine in the thyroid gland. Then, after the liberation, he became director of the National Centre of Scientific Research, and planned the reform and stimulation of scientific research in the whole of France. He has retired from this position on his recent appointment as High Commissioner for Atomic Energy, with direct responsibility to the President of the Provisional Government. These achievements are sufficiently remarkable, but to them is added great personal charm, which arouses the affection as well as the regard of his colleagues and friends. Prof. Joliot is a splendid representative of his people, and of French civilization, and his friends everywhere rejoice in his achievements and honours.

\section{Prof. Theodor von Kármán}

THEODOR VON KARMAN, professor of aeronautics and director of the Guggenheim Aeronautics Laboratory at the California Institute of Technology, Pasadena, is now the leading aeronautical scientist in the world. Born in Budapest in 1881, he left Hungary in 1906 , and by 1913 was director of the Aeronautical Institute at Aachen. In 1930 he settled in the United States, becoming an American citizen in 1936. During the War he was chief scientific adviser to the U.S. Army Air Corps. Kármán's researches in the theory of elasticity and its application to structures, and particularly in the mathematical theory of hydrodynamics and aerodynamics, and its applications to aeronautics, ballisties and hydraulics, show both great depth and great breadth of interest. In the teaching of aerodynamics and the hydrodynamics of real fluids, his work forms a substantial fraction of almost every course. Many phenomena and formula, now well known, bear his name; for example, the Kármán vortex-street, his method of boundary-layer calculation, the logarithmic resistance and heat-transfer formulæ, the solution for supersonic flow past projectile-shaped bodies, and so on.

Kármán's interests and influence, both in mathematics and engineering, are wider than his own research work. He has developed and directed two outstanding research centres, both of which achieved world-wide fame. Many engineering projects have been carried out under his guidance, and he has been officially consulted on many engineering problems. By books, lectures and personal example he has achieved a great and continuing influence on the rationalization of engineering practice wherever and whenever it became possible; and he has laboured successfully to present to mathematicians in a suitable form the difficult problems arising in engineering science.

\section{Dr. E. A. Stensiö}

Dr. ERIK ANDERsson Stensiö, of Stockholm, is perhaps the greatest living authority on the anatomical structure of fossil fishes. He has brought to his studies an ingenuity of technique that has not only been helpful in other fields but has wrested even from unpromising material a wealth of information, so that we know more of the structure of some of these fishes from a remote past than of many living repre. sentatives. Stensiö's account of the Triassic fishes of Spitsbergen published in 1921 was a most important contribution, and notable not merely because of the relative inaccessibility of the material but also because of the thoroughness of his account, which was illustrated by no less than thirty-five plates and ninety text figures, and the valuable comparison between these ancient types and the modern Ganoids and Teleosts. Other outstanding contributions were his studies of the Ostracoderms of Spitsbergen from the Silurian and Devonian rocks, and the monograph of the Cephalaspids of Great Britain which was pub. lished by the trustees of the British Museum.

\section{NEWS and VIEWS}

Scientific Adviser to the Army Council: Brigadier

\section{O. H. Wansbrough-Jones}

Brigadier O. H. WANSBRough-Jones, who has been appointed scientific adviser to the Army Council in succession to Sir Charles Ellis, was educated at Gresham's School, Holt, and became a scholar of Trinity Hall, Cambridge, in 1922. After taking his honours degree in chemistry, he commenced research work in the Department of Colloid Science in 1926 and has been connected with that Department ever since. In 1930 he was elected a fellow of his College. On obtaining his fellowship he spent some time with Haber in the Kaiser Wilhelm Institute in Berlin. On his return to Cambridge, his administrative abilities led him to the tutorship of Trinity Hall and a departmental demonstratorship in the Department of Colloid Science, posts which he held until the outbreak of war. In 1939 he joined the army and after a series of appointments terminated as Director of Special Weapons and Vehicles. The departure of Wansbrough-Jones is a serious blow to his College, in which he was rapidly establishing himself as one of the best tutors, in that he was able to preserve that balance between the sciences and the arts, between the affluent and the poor, between the specialist and those with broad interests, which is the foundation of a good democratic college. The recent rapid growth of the Civil Service spirit and its accompanying technique in the universities of Britain renders it almost essential for science departments to have somebody on their staff who ean translate and render intelligible the ever-increasing flow of notes, memoranda, return forms and the like, which are showered upon them. This admirable function was carried out by Wansbrough-Jongs for the Department 